DOI: 10.21767/2471-299X.1000034

\title{
AMD-OSDI Consensus on Injection Techniques for People with Diabetes Mellitus
}

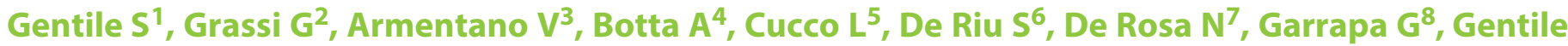
$L^{9}$, Giancaterini $A^{10}$, Lalli $C^{11}$, Lo Grasso $G^{12}$, Marcone TAM ${ }^{13}$, Chiandetti $R^{14}$, Speese $K^{15}$, Sudano $M^{16}$, Tatti ${ }^{17}$, Tonutti $L^{18}$, Branca $M^{19}$ and Strollo F20*

${ }^{1}$ Department of Clinical and Experimental Medicine, $2^{\text {nd }}$ University of Naples, Italy

${ }^{2}$ Endocrinology, Diabetes and Metabolic Disease Unit, Health and Science City Hospital, 'Molinette' Branch, Turin, Italy

${ }^{3}$ Diabetology Unit, ASL Napoli 1, Italy

${ }^{4}$ Unit for Clinical Nutrition and Metabolic Diseases, National Hospital S.G. Moscati, Avellino, Italy

${ }^{5}$ Endocrinology and Metabolic Disease Unit, ASL Pescara, Italy

${ }^{6}$ Unit for Diabetes and Metabolic Diseases, ASL Salerno 1, Salerno, Italy

${ }^{7}$ Diabetes Center, ASL Napoli-2 North, Naples, Italy

${ }^{8}$ Diabetes Unit, Fano Branch, Fano, Italy

${ }^{9}$ Unit for Diabetes and Metabolic Diseases, ASL AT Asti, Italy

${ }^{10}$ Unit for Chronic Care and Diabetes, Territory Hospital Clinical Specialization Institutes, Milan, Italy

${ }^{11}$ Diabetes and Endocrinology Unit, Hospital San Matteo degli Infermi, Spoleto, Italy

12 Endocrinology Unit, Garibaldi Medical Center of Catania, Italy

13 Diabetes Unit, University Hospital, Foggia, Italy

${ }^{14}$ University Hospital Santa Maria della Misericordia, Udine, Italy

${ }^{15}$ Trento Province Health Service Agency, Rovereto Diabetes Care Center (TN), Italy

${ }^{16}$ Unit for Diabetes and Metabolic Diseases, ASUR Marche AV1 Urbino, Italy

${ }^{17}$ Division of Endocrinology and Diabetes, ASL Roma H, Italy

${ }^{18}$ Unit for Diabetes, Endocrine and Metabolic Diseases, University Hospital, Udine, Italy

${ }^{19}$ Diabetes Unit, ASL Tricase, Lecce, Italy

${ }^{20}$ Endocrinology and Metabolism, Elle-di, Rome, Italy

${ }^{*}$ Corresponding author: Strollo F, Medical Resident, Endocrinology and Metabolism, Elle-di, Rome, Italy, Tel: 0039063219639; E-mail: felix.strollo@gmail.com

Received date: September 01, 2016; Accepted date: September 19, 2016; Published date: September 26, 2016

Copyright: (C 2016 Gentile S, et al. This is an open-access article distributed under the terms of the Creative Commons Attribution License, which permits unrestricted use, distribution, and reproduction in any medium, provided the original author and source are credited.

Citation: Gentile S, Grassi G, Armentano V, et al. AMD-OSDI Consensus on Injection Techniques for People with Diabetes Mellitus. Med Clin Rev. 2016, 2:3.

\section{Abstract}

It goes without saying that all people with diabetes should be taught the best injection technique before starting insulin treatment. Nevertheless the extremely high rate of local injection-related skin reactions-i.e., lipodysthrophic lesions-described in literature, proves otherwise.

We are hereby presenting a Consensus Document on Injecting Techniques which highlights 18 key points based on a thorough analysis of the available literature and ranked by "Level of evidence" and "Strength of recommendation" according to our National Guideline System.

It is meant at providing all professionals involved in diabetes care with a practical guide on how to help patients on insulin perform well.

Keywords: Insulin injections; Diabetes mellitus; Recommendations; Lipohypertrophy 


\section{Conflicts of Interest:}

None

\section{Abbreviations:}

AMD: Association of Clinical Diabetologists; OSDI: Italian Diabetes Healthcare Professionals; MD: Medical Doctor; Prof: Professor; HN: Head Nurse

\section{Was a Consensus Document on Injecting Techniques really needed?}

According to data from ISTAT (National Institute of Statistic) 2011 report [1] about 3 million people with diabetes mellitus (DM) are living in Italy nowadays, mostly in the South of our country, with a $5.1 \%$ prevalence of type 1 DM (T1DM). ARNO 2011 report, on the other side, witnessed in favour of a 10year lasting ever increasing utilization of newer insulin preparations endowed with a more physiological pharmacokinetics profile, such as rapid-acting and basal analogues, as well as, of innovative therapeutic regimes [2]. In spite of technological progresses, and a general improvement in the quality of care, the 2012 AMD Annals [3] reported that only $22.2 \%$ T1DM and $43.8 \%$ T2DM patients reached $\mathrm{HbA} 1 \mathrm{C}$ levels below 7\% (53 mmol/mol), and T2DM patients above $9 \%$ ( $75 \mathrm{mmol} / \mathrm{mol}$ ) accounted for $25.7 \%$ monitored people.

Many factors related to insulin administration, storage and handling might contribute to poor metabolic control. Therefore, a major goal of health care teams is to educate patients and caregivers to the best possible injectable drug administration techniques and the most skilful utilization of related available devices.

In order to let them reach that goal, we collected all available scientific evidences on this issue and organised it according to well-defined hierarchically distributed criteria targeted at patient's self-management/empowerment [4], and based on National Guideline System [5] with structured education on top. Our Consensus Document on Injecting Techniques represents in fact the final result of this strong clinical effort.

\section{Recommendations concerning injectable drug administration}

A correct injection technique is essential for insulin and other subcutaneously administered medications to ensure optimal effects in people with diabetes mellitus (DM). It implies the ability to (i) choose the best needles, (ii) rotate injection sites regularly, (iii) handle and store insulin appropriately, (iv) insert needles correctly into the skin, (v) let pen needles inside the skin long enough to get the whole dose be absorbed and (vi) manipulate the skin before and after injection (Table 1) (Level of evidence III, Strength of recommendation $B$ ).

Insulin must be injected into intact subcutaneous tissue and intramuscular shots have to be avoided, which would result into fast absorption and consequent risk of hypoglycaemia (Level of evidence II, Strength of recommendation B).

Insulin effects are not affected by injection depth, provided the latter falls within the subcutaneous tissue (Level of evidence V, Strength of recommendation B).

Injection site rotation within large surfaces, needle disposal after each shot and pinch technique utilization at a $45^{\circ}$ angle with respect to the skin whenever needles longer than $6 \mathrm{~mm}$ are chosen are essential factors to ensure optimal insulin absorption and prevent skin injury (Level of evidence II, Strength of recommendation A).

An effective rotation scheme consists of dividing injection site into quadrants and regularly spacing shots $1-2 \mathrm{~cm}$ apart from one another within each quadrant in order to avoid causing repeated traumas to the same site (Level of evidence I, Strength of recommendation A).

Rapid acting insulin analogues can be injected anywhere as their absorption is not site-dependent. On the opposite, regular human insulin is preferentially injected into the abdomen where absorption is faster and rather stable (Level of evidence I, Strength of recommendation A).

Areas of lipodystrophy can occur as a consequence of missed injection site rotation and needle reuse, especially when certain insulin preparations are chosen (Level of evidence III, Strength of recommendation B).

The choice of needle length (for either pens or syringes) is crucial to ensure optimal insulin absorption (Level of evidence III, Strength of recommendation B).

Injections performed with shorter and thinner needles cause less pain and discomfort and ensure better therapy acceptance and adherence (Level of evidence II, Strength of recommendation $\mathrm{A}$ ).

Injection with a pen and the use of shorter and thinner needles ensure optimal insulin absorption in thin patients and children. This approach does not require the pinch (or skinfold) technique to be used and is therefore easier to follow and to teach. It also causes less fear and pain, thus ensuring better therapy acceptance and adherence (Level of evidence II, Strength of recommendation A).

When injected into lipodystrophic areas, insulin gets altered in terms of pharmacokinetics and pharmacodynamics, which causes variable and unpredictable absorption and affects glycaemic control (Level of evidence II, Strength of recommendation $\mathrm{B})$.

When moving from a lipodystrophic area to a healthy zone, insulin dosage should be reduced because of expected improved absorption. Per cent reduction varies from person to person and should be guided by intensified self-monitoring blood glucose (Level of evidence II, Strength of recommendation $\mathrm{A}$ ).

All patients should be provided with appropriate education and training sessions by the diabetes care team before starting 
any treatment regimens based on drug injections (Level of evidence II, Strength of recommendation A).

Inspection and palpation of injection sites should be carried out systematically in all patients on subcutaneous therapy and education concerning proper injection techniques and injection site self-palpation should be systematically reinforced (Level of evidence II, Strength of recommendation A).

In the hospital pen needles and syringes have to comply with safety criteria to minimize any risks of accidental injuries and to keep health care providers, patients and relatives far from any hazards during all utilization phases including disposal (Level of evidence II, Strength of recommendation B).

Table 1: Levels of scientific evidence and the strength of recommendations as classified according to our National Guideline System (5).

\begin{tabular}{|c|c|}
\hline Levels of Evidence & Strength of Recommendations \\
\hline 1 & A \\
\hline \multirow{2}{*}{$\begin{array}{l}\text { Evidence from more than one controlled randomized clinical trials and/or } \\
\text { systematic reviews of randomized studies }\end{array}$} & The procedure or diagnostic test is strongly recommended. \\
\hline & $\begin{array}{l}\text { The recommendation is supported by high quality scientific evidence (not } \\
\text { necessarily type I or II) }\end{array}$ \\
\hline II & B \\
\hline Evidence from one properly designed randomized trial & $\begin{array}{l}\text { There are still doubts concerning whether or not the procedure or intervention } \\
\text { should always be recommended, but it is believed that it should be carefully } \\
\text { considered }\end{array}$ \\
\hline III & $\mathrm{C}$ \\
\hline $\begin{array}{l}\text { Evidence from non-randomized cohort studies with concurrent or historical } \\
\text { control or their meta-analysis }\end{array}$ & $\begin{array}{l}\text { Whether or not to recommend the procedure or intervention is still a matter of } \\
\text { debate }\end{array}$ \\
\hline IV & $\mathrm{D}$ \\
\hline $\begin{array}{l}\text { Evidence from retrospective studies, such as case-control, or their meta- } \\
\text { analysis }\end{array}$ & The procedure is not recommended \\
\hline $\mathrm{V}$ & $E$ \\
\hline Evidence from case studies ("case series") without any control group & The procedure is strongly discouraged \\
\hline VI & - \\
\hline $\begin{array}{l}\text { Evidence based on expert opinion or authoritative expert committees as } \\
\text { indicated in guidelines or consensus conferences, or based on opinions of } \\
\text { members of the working group responsible for the present guidelines }\end{array}$ & \\
\hline
\end{tabular}

\section{Comments}

In order to ensure that injected insulin profile keeps in line with expected pharmacokinetics and pharmacodynamics, thus yielding predictable biological effects, it is necessary to perform a correct injection technique [6-9] as avoidable errors might modify insulin action [10,11]. Since they have to deal with a daily treatment, patients with DM are at risk for progressively increasing careless and incorrect habits which in turn are expected to increase glycaemic variability over time [10].

To get optimal absorption, insulin must be injected into the subcutaneous tissue, not into the dermis or into the muscle. That's why the choice of needle length is crucial. The latter is greater with syringes than with pens and therefore, when allowed to, people with DM choose pens. Nevertheless, it has been proven that, when a proper injection protocol is made available also to special populations like AIDS, HBV or HCV infected patients (Level of evidence II, Strength of recommendation $\mathrm{B}$ ).

According to safety rules aimed at minimizing the risk for any infection transfer among patients, each insulin pen should be utilized in the hospital for a single individual only (Level of evidence II, Strength of recommendation B).

Insulin storage should comply anywhere with approved producer's leaflet. This should also be the object of careful patient education (Level of evidence II, Strength of recommendation $\mathrm{B}$ ).
Home utilization of safety needles and syringes should be 
glucose levels is recommended under these circumstances $[24,25]$.

Subcutaneous tissue thickness varies significantly depending on sex, body mass index, age, ethnicity, diabetes type, morphology of the diabetic individual, as well as, on pressure exerted during injection $[8,11,14]$. The risk of intramuscular injections depends on that all and has been estimated to be $15.3 \%$ with $8 \mathrm{~mm}, 5.7 \%$ with $6 \mathrm{~mm}$ and $0.4 \%$ with $4 \mathrm{~mm}$ needles [14,26-28].

Injection site rotation within large surfaces, needle disposal after each shot and $45^{\circ}$ angle pinch technique utilization with needles $>6 \mathrm{~mm}$ are essential factors to ensure optimal insulin absorption and prevent skin injury [11,15,22,29-34].

With the advent of insulin analogues, absorption varies much less both between and within individuals and is therefore more predictable and easier to handle by the patient [30]. However, despite technological advances allowing newer and newer insulin analogue availability, certain absorption/ action affecting factors still remain, such as exercise, counterregulatory hormones, high dosage, incorrectly mixed preparations or even the habit to pull out needles from the skin too early after pen pistons reaching their end stroke positions [29,30]. Another example of how the injection technique may affect insulin pharmacokinetics is given by glargine [31]: Its long acting effect is based on its ability to precipitate within the subcutaneous tissue at $\mathrm{pH} 7$, and cannot be exploited in case of intramuscular injections, which thus cause unexpected hypoglycaemic episodes [30].

Insulin absorption does not vary as a function of how deep it reaches into the subcutaneous tissue. However, the use of the same anatomical region for shots performed at the same time of day and the choice of abdomen before meals [24] are recommended only for different types of human insulin preparation [6-8], which also of course require to regularly inject the drug at a distance of about $2 \mathrm{~cm}$ from previous shots within each region in order to avoid repeated traumas.

So, to summarize all the above, the choice of delivery devices and needle length has been proven to affect insulin absorption and, independently of using pens or syringes, the needle influences correct techniques the most. Nowadays insulin syringes with needles less than $8 \mathrm{~mm}$ are not available in our country and their use without pinching the skin and injecting at a $45^{\circ}$ angle increases the risk of intramuscular injections. Therefore we suggest using pens with short needles $(4 \mathrm{~mm})$ just to minimise the risk of intramuscular injections. Also needle gauge (G) and sharpness are important factors in terms of patient acceptance and satisfaction [32-35]. $4 \mathrm{~mm} \times$ $32 \mathrm{G}$ needles provide both obese and non-obese patients with comparable degrees of metabolic control as $5 \mathrm{~mm} \times 31 \mathrm{G}$ and 8 $\mathrm{mm} \times 31 \mathrm{G}$ needles but are perceived as less painful and better accepted [34,36-39].

Injecting insulin by shorter and thinner pen needles $(4 \mathrm{~mm}$ and $32 \mathrm{G}$ ) with triple bevels, in compliance with the UNI EN ISO 7864 standards, cause less pain and discomfort [14,36,39-40] and ensure better therapy acceptance and adherence. In fact, the greater the outer diameter, the greater the resistance the needle has to face to penetrate the skin and, vice versa, the smaller the outer diameter, the less the feeling of discomfort at injection.

One of the most common complications of such treatment is the development of cutaneous lipodystrophy, also described with continuous insulin infusion systems [41-43]. Its exact aetiology is not entirely clear yet, although several causative factors are implicated, such as repeated traumas into very limited areas, needle re-use, insulin per se as a growth factor, especially at a high doses, and old protaminated/human insulin $[22,44]$. The risk of lipohypertrophy is $31 \%$ higher in subjects using the same needle several times than in the others [11].

Lipodystrophies are widespread. Vardar and Kizilci [45] reported a prevalence of $48.8 \%$ in 215 Turkish patients treated with insulin for at least two years; according to Hauner et al. [46], in 233 German patients with DMT1 the prevalence was 28.7\%. More recently, Blanco et al. [11] documented lipodystrophy in as many as $64.4 \%$ investigated patients, with a strong relationship to incorrect site rotation habits. In addition, 39.1\% patients with lipohypertrophy showed unexplained hypoglycaemia and $49.1 \%$ had high glycaemic variability. Several studies show that insulin absorption from lipodystrophic areas can be delayed or become unpredictable [47-50], thus representing a potential factor of worsening glycaemic control [50-58], while the use of very short needles is preferred by patients $[35,37,38]$ and is less traumatic per se $[39,42]$.

\section{Education}

Insulin therapy is a long-lasting patient commitment day after day putting them at risk for more and more careless and incorrect habits in the absence of any proper and consistent educational support. As a consequence of that glycaemic variability and poor metabolic control are expected to increase [10].

Appropriate education on injection techniques is obviously essential, nevertheless it is often lacking [4], as shown by the high rate of skin lesions caused by incorrect injecting habits [11,36,38-50].

Diabetes care teams must promote patient empowerment to let people understand what is best for them day by day. In particular, insulin self-administration requires specific skills to be acquired to perform injections correctly.

Patients need to understand the close relationship between injection technique and metabolic control [59], as well as, changes in pharmacokinetics expected to occur with incorrect injection techniques and consequent increased risk of chronic complication onset/acceleration $[10,11,14,15]$.

All patients starting injections should be accurately educated on proper techniques [23,32,54-56]. Education should also be regularly reinforced and healthcare professionals are expected to perform inspection and palpation interested sites on a regular, systematic basis in all subjects on injection therapy $[26,36,48,54,58,60-62]$ and 
especially in those facing repeated unexplained hypoglycaemic episodes [11]. Education should not be limited to treatment start, it should rather go on throughout the whole follow-up period with timely reinforcements [63], put special emphasis on the negative effects of getting into the muscle tissue or into altered skin areas.

People with diabetes should also learn that self-monitoring blood glucose has to be intensified when moving from longer to shorter needles and/or from healthy to altered skin areas $[8,11,50,51]$.

An appendix on insulin appears in an attachment in "AMD Algorithms Online - The personalisation of therapy in type 2 diabetes" and can be consulted on the AMD website: at http:// www.aemmedi.it/pages/linee-guida_e_raccomandazioni/.

\section{Training of healthcare providers}

Diabetes teams should follow systematically the simple procedure for the diagnosis of lipohypertrophy reported in a previous paper from our group and try to get it further implemented and progressively refined in large scale studies.

Briefly it can be summarized as follows: The health care professional should (i) inspect each interested area first, using direct and tangential light against a dark background; (ii) touch the skin at the beginning and progressively increase finger pressure thereafter; (iii) fine-tune palpation by performing slow circular and vertical fingertip movements followed by repeated horizontal attempts on the same spot; and (iv) perform the pinch maneuver when perceiving a harder skin by comparing suspected spot to surrounding areas in terms of thickness.

This would have a major impact on education not only in terms of correct injection technique per se but also to allow patients to identify lipodystrophic areas themselves early and easily enough to avoid them and thus prevent poor metabolic outcomes [58-64].

\section{Summary and future outlook}

To summarize all of the above, in insulin-treated patients a number of actions have to be implemented to minimize the risk of lipodystrophy due to incorrect injection techniques, which are hereby listed in the shape of a set of personalized practical hints:

\section{- For insulin pen users:}

1. $4 \mathrm{~mm} / 32 \mathrm{G}$ needles should be preferred regardless of $\mathrm{BMI}$, age, sex, and race;

2. The pinching technique should be used in extremely thin patients or in young children;

3. Needles should be changed at each injection, "one needle, one injection";

4. Each injection should always be made at least $2 \mathrm{~cm}$ apart from the previous one;
5. Injection sites should be constantly rotated within and among different locations (arms, thighs, abdomen, buttocks).

\section{- For insulin syringe users:}

1. The shortest available needles should be chosen (currently $8 \mathrm{~mm}$ );

2. The pinching technique should always be used at each site;

3. Points 3, 4, and 5, for pens users also apply to syringe users.

\section{- For CSII users:}

1. Shorter needles are mostly preferred;

2. Needle insertion at $45^{\circ}$ angle is also preferred;

3. Each needle should not be kept there longer than three days;

4. Points 4, and 5, for pens users also apply to CSII users.

\section{- For any patients using any devices:}

1. It is essential to start structured education before starting insulin and have patients attend periodic follow-up refresher courses;

2. Health care providers should make patients understand the need for proper injection techniques;

3. Patients should learn how to perform careful skin selfexamination prior to each injection systematically in order to skip any lipodystrophic area.

For the future we envisage the following actions to be taken:

\section{- Unmeet needs}

1. EBM indications on proper injection techniques should be included in all guidelines when it comes to insulin therapy;

2. Further studies are needed to define the best possible educational follow-up strategies;

3. Further studies are warranted to define the risk of local injection-related side effects for all other injecting drugs meant for diabetes treatment.

\section{References}

Diabete in Italia Anni 2000-2011. ISTAT (2012) http:// www.istat.it/it/archivio/71090

2. Osservatorio ARNO Diabete. II profilo assistenziale della popolazione con diabete (2011) Volume XVII - Collana "Rapporti ARNO" Cineca-Dipartimento SISS-Sanità. file:///C:/Documents \%20and\%20Settings/Administrator/Documenti/Downloads/ RapportoARNO2011. pdf.

3. Gli Annali AMD (2012) Analisi prospettica degli indicatori di qualità dell'assistenza del Diabete in italia (2004-2011)http:// www.infodiabetes.it/files/ANNALI-AMD/2012/_ Annali \%202012.pdf. 
4. Raccomandazioni di trattamento assistenziale in campo diabetologico-Position statement OSDI (2012) Somministrazione di Insulina: Aspetti Tecnici ed Educativi. http://www.osdi.it/ Uploads/Raccomandazioni/Raccomandazioni_01.pdf.

5. (2015) National Guideline System. http://www.snlg-iss.it/

6. Thow J (1990) Home P. Insulin injection technique. Br Med J 301: 3-4.

7. Diabetes Care in the UK (2002) The First UK Injection Technique Recommendations (2nd edn.). www.trend-uk.org/

8. Frid A, Hirsch L, Gaspar R, Hicks D, Kreugel G, et al. (2010) New injection recommendations for patients with diabetes. Diabetes Metab 36: S3-S18.

9. De Coninck C, Frid A, Gaspar R, Hicks D, Hirsch L, et al. (2010) Results and analysis of the 2008-2009 Insulin Injection Technique Questionnaire survey. J Diabetes 2: 168-179.

10. Frid A, Linden B (1986) Where do lean diabetics inject their insulin? A study using computed tomography. Br Med J 292: 1638.

11. Blanco M, Hernández MT, Strauss KW, Amaya ME (2013) Prevalence and risk factors of lipohypertrophy in insulininjecting patients with diabetes. Diab Metab 39: 445-463.

12. Jørgensen JO, Flyvbjerg A, Jørgensen JT, Sørensen HH, Johansen $B R$, et al. (1988) NPH insulin administration by means of a pen injector. Diabet Med 5: 574-576.

13. Korytkowski M, Bell D, Jacobsen C, Suwannasari R (2003) FlexPen Study Team. A multicenter, randomized, openlabel, comparative, two-period crossover trial of preference, efficacy, and safety profiles of a prefilled, disposable pen and conventional vial/syringe for insulin injection in patients with type 1 or 2 diabetes mellitus. Clin Ther 25: 2836-2848.

14. Gibney MA, Arce CH, Byron KJ, Hirsch LJ (2010) Skin and subcutaneous adipose layer thickness in adults with diabetes at sites used for insulin injections: implications for needle length recommendations. Curr Med Res Opin 26: 1519-1530.

15. Thow JC, Coulthard A, Home PD (1992) Insulin injection site tissue depths and localization of a simulated insulin bolus using a novel air contrast ultrasonographic technique in insulin treated diabetic subjects. Diabet Med 9: 915-920.

16. Lo Presti D, Ingegnosi C, Strauss K (2012) Skin and subcutaneous thikness at injecting sites in children with diabetes: ultrasound findings and recommendations for giving injection. Pediatr Diabetes 13: 525-533.

17. Birkebaek NH, Johansen A, Solvig J (1998) Cutis/subcutis thickness at insulin injections and localization of simulated insulin boluses in children with type 1 diabetes mellitus: need for individualization of injection technique? Diabet Med 15: 965-971.

18. Tubiana-Rufi N, Belarbi N, Du Pasquier-Fediaevsky L, Polak M, Kakou B, et al. (1999) Short needles reduce the risk of intramuscular injections in children with type 1 diabetes. Diabetes Care 22: 1621-1625.

19. Polak M, Beregszaszi M, Belarbi N, Benali K, Hassan M, et al. (1996) Subcutaneous or intramuscular injections of insulin in children: are we injecting where we think we are? Diabetes Care 19: 1434-1436.

20. Vaag A, Handberg A, Lauritzen M, Henriksen JE, Pedersen KD, et al. (1990) Variation in absorption of NPH insulin due to intramuscular injection. Diabetes Care 13: 74-76.
21. Smith CP, Sargent MA, Wilson BPM, Price DA (1991) Subcutaneous or intramuscular insulin injections. Arch Dis Childhood 66: 879-882.

22. Richardson T, Kerr D (2003) Skin-related complications of insulin therapy: epidemiology and emerging management strategies. Am J Clin Dermatol 4: 661-667.

23. American Diabetes Association Position Statements (2004) Insulin administration. Diabetes Care 27: S106-S107.

24. Clinical guideline [CG15] (2004) Type 1 diabetes: Diagnosis and management of type 1 diabetes in children, young people and adults. http://www.nice.org.uk/guidance/CG15

25. Jamal R, Ross SA, Parkes JL, Pardo S, Ginsberg BH, et al. (1999) Role of injection technique in use of insulin pens: prospective evaluation of a 31-gauge, 8-mm insulin pen needle. Endocr Pract 5: $245-250$.

26. Hofman PL, Lawton SA, Peart JM, Holt JA, Jefferies CA, et al. (2007) An angled insertion technique using 6-mm needles markedly reduces the risk of intramuscular injections in children and adolescents. Diabet Med 24: 1400-1405.

27. Strauss K, Hannet I, McGonigle J, ParkesJ, Ginsberg B, et al. (1999) Ultra-short $(5 \mathrm{~mm})$ insulin needles: trial results and clinical recommendations. Pract Diabetes Int 16: 218-222.

28. Hofman PL, Derraik JG, Pinto TE, Tregurtha S, Faherty A, et al. (2010) Defining the ideal injection techniques when using 5-mm needles in children and adults. Diabetes Care 33: 1940-1944.

29. Strauss K, De Gols H, Hannet I, Partanen TM, Frid A, et al. (2002) A Pan-European epidemiologic study of insulin injection technique in patients with diabetes. Pract Diab Int 19: 71-76.

30. Guerci B, Sauvanet JP (2005) Subcutaneous insulin: pharmacokinetic variability and glycemic variability. Diabetes Metab 31: 4S7-4S24.

31. Karges B, Boehm BO, Karges W (2005) Early hypoglycaemia after accidental intramuscular injection of insulin glargine. Diabet Med 22: 1444-1445.

32. Hansen B, Matytsina I (2011) Insulin administration: selecting the appropriate needle and individualizing the injection technique. Expert Opin Drug Deliv 8: 1395-1406.

33. Kreugel G, Beijer HJM, Kerstens MN, Maaten JC, Sluiter WJ, et al. (2007) Influence of needle size for subcutaneous insulin administration on metabolic control and patient acceptance. Eur Diabetes Nur 4: 51-55.

34. Hirsch GJ, Michael A, Gibney, Albanese J, Qu S (2010) Comparative glycemic control, safety and patient ratings for a new $4 \mathrm{~mm} \times 32 \mathrm{G}$ insulin pen needle in adults with diabetes. Curr Med Res Opin 26: 1531-1541.

35. Schwartz S, Hassman D, Shelmet J, Sievers R, Weinstein R, et al. (2004) A multicenter, open-label, randomized, two-period crossover trial comparing glycemic control, satisfaction, and preference achieved with a31gauge $\times 6 \mathrm{~mm}$ needle versus a 29 gauge $\times 12.7 \mathrm{~mm}$ needle in obese patients with diabetes mellitus. Clin Ther 26: 1663-1678.

36. Birkebaek NH, Solvig J, Hansen B, Jorgensen C, Smedegaard J, et al. (2008) A 4-mm needle reduces the risk of intramuscular injections without increasing backflow to skin surface in lean diabetic children and adults. Diabetes Care 31: e65.

37. Mc Grath PA (1989) Evaluating a child's pain. J Pain Symptom Manage 4: 198- 214. 
38. Egekvist H, Bjerring P, Arendt-Nielsen L (1999) Pain and mechanical injury of human skin following needle insertions. Eur J Pain 3: 41-49.

39. Aronson R (2012) The role of comfort and discomfort in insulin therapy. Diabetes Technol Ther 14: 741-747.

40. Kreugel G, Keers JC, Kerstens MN, Wolffenbuttel BH (2011) Randomized trial on the influence of the length of two insulin pen needles on glycemic control and patient preference in obese patients with diabetes. Diabetes Technol Ther 13: 737-741.

41. Radermecker RP, Piérard GE, Scheen AJ (2007) Lipodystrophy reactions to insulin: effects of continuous insulin infusion and new insulin analogs. Am J Clin Dermatol 8: 21-28.

42. Griffin ME, Feder A, Tamborlane WV (2001) Lipoatrophy associated with lispro insulin in insulin pump therapy: an old complication, a new cause? Diabetes Care 24: 174.

43. Ampudia-Blasco FJ, Hasbum B, Carmena R (2003) A new case of lipoathrophy with lispro insulin in insulin pump therapy: is there any insulin preparation free of complications? Diabetes Care 26 953-954.

44. Thow JC, Johnson AB, Marsden S, Taylor R, Home PH, et al. (1990) Morphology of palpably abnormal injection sites and effects on absorption of isophane (NPH) insulin. Diabetic Med 7: 795.

45. Vardar B, Kizilci S (2007) Incidence of lipohypertrophy in diabetic patients and a study of influencing factors. Diabetes Res Clin Pract 77: 231-236.

46. Hauner H, Stockamp B, Haastert B (1996) Prevalence of lipohypertrophy in insulin-treated diabetic patients and predisposing factors. Exp Clin Endocrinol Diabetes 104: 106-110.

47. Holstein A, Stege H, Kovacs P (2010) Lipoatrophy associated with the use of insulin analogues: a new case associated with the use of insulin glargine and review of the literature. Expert Opin Drug Saf 9: 225-231.

48. Johansson U, Amsberg S, Hannerz L, Wredling R, Adamson U, et al. (2005) Impaired absorption of insulin aspart from lipohypertrophic injection sites. Diabetes Care 28: 2025-2027.

49. Young RJ, Hannan WJ, Frier BM, Steel JM, Duncan LJ, et al. (1984) Diabetic lipohy-pertrophy delays insulin absorption. Diabetes Care 7: 479-480.

50. Chowdhury TA, Escudier V (2003) Poor glycaemic control caused by insulin induced lipohypertrophy. Br Med J 327: 383-384.

51. Wallymahmed ME, Littler P, Clegg C, Haqqani MT, Mac-Farlane IA, et al. (2004) Nodules of fibro-collagenous scar tissue induced by subcutaneous insulin injections: a cause of poor diabetic control. Postgrad Med J 80: 732-733.

52. Robertson C (2006) Physiologic insulin replacement in type 2 diabetes: optimizing postprandial glucose control. Diabetes Educ 32: 423-432.

53. Gentile S, Agrusta M, Guarino G, Carbone L, Cavallaro V, et al. (2011) Metabolic consequences of incorrect insulin administration techniques in aging subjects with diabetes. Acta Diabetol 48: 121-125.

54. Heinemann L (2010) Insulin Absorption from Lipodystrophic Areas: A (Neglected) Source of Trouble for Insulin Therapy? J Diabetes Sci Technol 4: 750-753.

55. Alemzadeh R, Loppnow C, Parton E, Kirby M (2003) Glucose sensor evaluation of glycemic instability in pediatric type 1 diabetes mellitus. Diabetes Technol Ther 5: 167-173.

56. De Meijer PHEM, Lutterman JA, van Lier HJJ, van'tLaar A (1990) The variability of the absorption of subcutaneously injected insulin: effect of injection technique and relation with brittleness. Diabetic Med 7: 499-505.

57. Overland J, Molyneaux L, Tewari S, Fatouros R, Melville P, et al. (2009) Lipohypertrophy: does it matter in daily life? A study using a continuous glucose monitoring system. Diab Obes Metab 11: 460-463.

58. Saez-de Ibarra L, Gallego F (1998) Factors related to lipohypertrophy in insulin-treated diabetic patients: role of educational intervention. Pract Diab Int 15: 9-11.

59. NHS Diabetes Annual Care Review. Diabetes.co.uk. (2016)http://www.diebetes.org.uk/manage/annual.htm0

60. Seyoum B, Abdulkadir J (1996) Systematic inspection of insulin injection sites for local complications related to incorrect injection technique. Trop Doct 26: 159-161.

61. Annersten M, Willman A (2005) Performing subcutaneous injections: a literature review. Worldviews Evid Based Nurs 2: 122-130.

62. Partanen T, Rissanen A (1998) Insulin injection practices. Pract Diabetes Int 17: 252-254.

63. Saez-de I, Gallego F (1998) Factors related to lipohypertrophy in insulin-treated diabetic patients: role of educational intervention. Pract Diab Int 15: 9-11.

64. Goudswaard AN, Stolk RP, Zuithoff NP, de Valk HW, Rutten GE, et al. (2004) Long-term effects of self-management education for patients with Type 2 diabetes taking maximal oral hypoglycaemic therapy: a randomized trial in primary care. Diabet Med 21: 491-496. 